\title{
XENOFOBIA Y RACISMO HACIA (Y POR) INMIGRANTES VENEZOLANOS RESIDENTES EN PERÚ A TRAVÉS DE TWITTER
}

\section{XENOPHOBIA AND RACISM TOWARDS (AND FROM) VENEZUELAN IMMIGRANTS RESIDENTS IN PERU THROUGH TWITTER}

\author{
Orlando Nikolai Santos Alvarado \\ Universidad Nacional Mayor de San Marcos, Perú \\ (iD) https://orcid.org/0000-0002-7490-3048
}

Autor para correspondencia: Orlando Nikolai Santos Alvarado, email: orlando.santos@unmsm.edu.pe

\section{Resumen}

El presente trabajo tiene por objetivo examinar las formas de la exteriorización discursiva de la xenofobia y el racismo de los internautas peruanos hacia los inmigrantes venezolanos residentes en Perú a través de Twitter, así como las respuestas a los discursos xenófobos y racistas que exteriorizan los internautas inmigrantes $u$ otros internautas peruanos. Para llevar a cabo este propósito se usaron algoritmos de web-scraping escritos en el lenguaje R. Asimismo, la gran cantidad de información recogida permitió dividir el análisis en dos etapas; la primera fue cuantitativa (análisis descriptivo), y la segunda fue cualitativa (análisis de contenido). Los resultados indican que la xenofobia y el racismo afectan de manera diferenciada a la población femenina inmigrante respecto del total de la población inmigrante. Además, se encontró que discursivamente la xenofobia y el racismo siguen dos direcciones, de los internautas peruanos hacia los inmigrantes y de los internautas inmigrantes hacia los peruanos. Como conclusión, se bosquejan posibles líneas de investigación que podrían surgir de este análisis pionero sobre la xenofobia y el racismo en Perú.

Palabras clave: xenofobia, racismo, inmigración venezolana, análisis del discurso, Twitter.

\begin{abstract}
This research aims to examine the discursive forms of the externalization of xenophobia and racism from Peruvian internet users towards Venezuelan immigrants residing in Peru through Twitter, as well as responses to xenophobic and racist discourses that immigrant Internet users or other Peruvian Internet users externalize. To carry out this purpose, web-scraping algorithms written in the R language were used. Also, the large amount of information collected allowed the analysis to be divided into two stages, first a quantitative stage (descriptive analysis) and secondly a qualitative stage (content analysis). Results indicate that xenophobia and racism affect
\end{abstract}

Global Media Journal México, 18(34), 160-184, enero - junio 2021. 
the immigrant female population differently from the total immigrant population. In addition, xenophobia and racism were found to follow two directions, from Peruvian Internet users to immigrants and from immigrant Internet users to Peruvians. In conclusion, possible lines of investigation are outlined that could arise from this pioneer analysis of xenophobia and racism in Peru.

Keywords: xenophobia, racism, Venezuelan immigration, speech analysis, Twitter.

Recibido: $11 / 04 / 2021$

Aceptado: 24/06/2021

\section{Introducción}

Un fenómeno que se ha hecho cada vez más común en los últimos años es la exteriorización de discursos abiertamente xenófobos y racistas que se difunden a través de plataformas virtuales. Uno de los ejemplos más notables de esta tendencia lo encontramos en el uso que Donald Trump le dio a su cuenta de Twitter (@realDonaldTrump ${ }^{1}$ ) como herramienta de comunicación política desde el inicio de su carrera para alcanzar la Casa Blanca en 2015. Su cuenta sirvió como el espacio desde el que difundía un discurso abiertamente racista y xenófobo que le hizo ganar el voto de los ciudadanos estadounidenses que compartían su xenofobia, la cual tuvo como máxima expresión a la promesa electoral del muro en la frontera mexicano-estadounidense (Ott, 2016).

Pero, más allá de Estados Unidos, este fenómeno acontece en casi todos los países que reciben grandes flujos migratorios desde el extranjero, tanto en países desarrollados como en los

\footnotetext{
${ }^{1}$ La cuenta de Donald Trump fue suspendida por Twitter
} en enero de 2021 alegando "riesgos de mayor incitación a en vía de desarrollo, y por ello el mundo académico de estos países le ha prestado atención a esta problemática. Así, Nguyen (2015) estudió el discurso racista de los estadounidenses en Twitter. En Europa, Miller et al. (2017) estudiaron la xenofobia en el contexto del Brexit, y Kreis (2017), con respecto a la crisis de refugiados sirios y africanos. En otro contexto, van der Vyver (2019) estudió la xenofobia hacia inmigrantes subsaharianos en Sudáfrica; sin embargo, en Latinoamérica no existen estudios específicos sobre este tema, pero si sobre discursos xenófobos, como los que Vidal y Tenorio (2018) y Torre (2019) realizaron en Brasil y México, respectivamente.

Desde el punto de vista metodológico, la mayoría de los estudios revisados sobre discurso en plataformas virtuales se caracterizan por extraer pequeñas muestras de información de manera manual. Solo los estudios de Nguyen (2015), Miller et al. (2017) y van der Vyver (2019) hacen uso de métodos computacionales para extraer grandes muestras de información (el estudio de Miller et al.

la violencia" (Pupiales, 2021) luego de los hechos de violencia ocurridos días antes.

Global Media Journal México, 18(34), 160-184, enero - junio 2021. 
analiza más de 200 mil tuits). Aunque extraer muestras pequeñas de manera manual no es necesariamente erróneo, puede afirmarse que es una estrategia metodológica que limita el panorama de la información que se obtiene de Internet pues en aquel caso los datos se recaban con base en los fines y las limitadas capacidades del investigador, lo que lleva el riesgo de caracterizar a las plataformas virtuales como él quiere verlas y no como realmente son. En contraste, la extracción y procesamiento de grandes muestras de información de Internet ayuda a tener un panorama de cuáles son las ideas que se expresan con relación a determinadas temáticas. Debido a ello, en esta investigación se hará uso de métodos computacionales para extraer grandes muestras de información y hacer un análisis descriptivo de la misma que permita guiar la búsqueda de información representativa para un análisis cualitativo posterior. Se espera que los resultados de la aplicación de los métodos computacionales y del análisis cualitativo puedan dar luz sobre cuáles son los discursos xenófobos y/o racistas que los internautas peruanos expresan en Twitter.

\section{Marco teórico}

Una mirada rápida al estudio de las problemáticas intergrupales en Perú muestra que generalmente se ha enfocado en el racismo que existe hacia los grupos menos favorecidos socialmente, con especial énfasis en las poblaciones de origen andino, tal como se puede observar en los trabajos de Portocarrero (2007) o Bruce (2007). Junto a ello, los estudios de Espinosa et al. (2007) y de Pancorbo et al. (2011) hacen una exploración de los prejuicios hacia diversos grupos étnicos que conviven en Lima desde el punto de vista de personas que residen en distritos de ingresos medio-altos y de personas que residen en distritos de ingresos bajos, respectivamente. Por otro lado, el estudio de Santos (2014) cuestiona los estudios sobre racismo en Perú. Junto a todos estos estudios, el trabajo de Manrique (2016) es el único trabajo sociológico sobre racismo e Internet en Perú. La conclusión que se puede extraer es que existen suficientes estudios sobre la problemática racial en Perú con referencia a los grupos étnicos que tradicionalmente lo han habitado.

Sin embargo, los estudios sobre xenofobia y racismo hacia poblaciones inmigrantes extranjeras en Perú son muy escasos (presumiblemente porque Perú no ha sido un país receptor de inmigración extranjera desde la segunda mitad del siglo XX), por lo que un estado de la cuestión sobre este tema debe tener en cuenta los estudios hechos en Latinoamérica y otras partes del mundo para tener una primera aproximación de cómo podría estar presentándose la xenofobia en Perú.

Con respecto a la xenofobia, esta ha sido considerada como un fenómeno casi indistinguible del racismo, en especial de las nuevas formas de racismo basadas en la cultura (Stavenhagen y Negrete, 1994; Torre, 2019; Traverso, 2012). Sumado a ello, los trabajos de Echebarría y Gonzales (1996) y Cea D'ancona (2009) añaden la dimensión de clase como característica de la xenofobia, pues estos trabajos muestran que la xenofobia no solo está 
referida al rechazo hacia los inmigrantes per se, sino principalmente al rechazo hacia los inmigrantes por ser pobres (o provenir de algún país pobre), de modo que el grado de aceptación del inmigrante parece depender de los recursos económicos que posea. Esto es algo que la literatura contemporánea ha denominado como "aporofobia" o rechazo a los pobres (Cortina, 2017).

A su vez, Stavenhagen y Negrete (1994) relaciona las raíces de la xenofobia con los intentos de consolidación interna y externa de los Estados nacionales en su afán de crear una identidad nacional distinguible de otras. Además, Hjerm (1998) matiza este tipo de afirmaciones al distinguirlas en identidades nacionales cívicas y étnicas, de modo que las últimas están más relacionadas con la xenofobia. Por otro lado, Cea D'ancona (2005) señala que las épocas de crisis o de recesión económica, en las que los inmigrantes están dispuestos a trabajar por salarios más bajos y en peores condiciones laborales, son contextos que propician la exteriorización de la xenofobia. Esto coincide con autores que señalan que el mayor énfasis en las manifestaciones xenófobas está en las capas sociales más pobres, aquellas que se sienten más amenazadas por la transformación de la naturaleza del Estado nacional debido al avance del proceso globalizador (Stavenhagen y Negrete, 1994; Torre, 2019) y que, por consiguiente, ven a los inmigrantes como una amenaza a esa idea de nación, convirtiéndolos en chivos expiatorios de? las más diversas situaciones (Traverso, 2012). Otros detonantes de la exteriorización de la xenofobia son los medios de comunicación que tienden a sobrerrepresentar a las minorías inmigrantes en noticias sobre delitos comunes, y los discursos políticos en épocas de campaña electoral que usan la supuesta amenaza inmigrante para movilizar a los votantes a su favor (Cea D'ancona, 2005; Ott, 2016).

La literatura sobre el tema ha identificado ciertos tipos de discursos que se suelen hallar cuando las personas debaten o son consultadas para expresar su opinión sobre los inmigrantes. Esos discursos por lo general adoptan la estrategia de la autopresentación positiva y heteropresentación negativa (Kreis, 2017; Torre, 2019) y los clasificamos de la siguiente manera:

Tipo 1: Discursos que señalan a los comportamientos supuestamente desviados de los inmigrantes como amenaza a la identidad nacional (Alonso, 2018; Cea D’ancona, 2005, 2009; Torre, 2019). Tienden a incidir en la cultura y costumbres de los inmigrantes. Estos discursos inciden en que los inmigrantes son una amenaza a los valores que cimentan la identidad nacional, y con base en esta identidad algunos individuos se sienten legitimados para discriminar a otros pues la presencia de los inmigrantes amenaza su idea de identidad nacional debido a sus normas y valores diferentes (Kreis, 2017).

Tipo 2: Discursos que señalan al inmigrante como amenaza económica (Cea D’ancona, 2005; Torre, 2019). Estos discursos tienden principalmente a ser expresados por personas de pocos ingresos que se sienten amenazadas económicamente en el mercado de trabajo, en especial en las ocupaciones menos remuneradas. 
Tipo 3: Discursos que señalan al inmigrante como amenaza de seguridad pública (Alonso, 2018; Kreis, 2017; Torre, 2019; Vidal y Tenorio, 2018). Estos discursos se usan tanto para denunciar supuestos aumentos de criminalidad generados por los inmigrantes, así como para celebrar el castigo hacia inmigrantes infractores. En el caso específico de Europa Occidental, Alonso (2018) señala que además de la delincuencia, se añade como amenaza de seguridad al terrorismo, relacionado con la minoría musulmana.

Tipo 4: Discursos que señalan al inmigrante como amenaza a la salud pública (Torre, 2019). El referido autor encuentra que este tipo de discursos suelen estar contextualizados en comentarios acerca de trabajos insalubres ejercidos por inmigrantes, como la prostitución.

Tipo 5: Discursos que exigen tratamiento favorable al nacional frente al inmigrante (Alonso, 2018; Cea D'ancona, 2005, 2009; Kreis, 2017). Estos discursos también se manifiestan como rechazo de cualquier ayuda hacia los inmigrantes y tienden a ser expresados por personas de pocos ingresos que se sienten amenazadas económicamente. A su vez, estos comentarios suelen ir acompañados de críticas hacia la administración estatal por su supuesto apego a los inmigrantes o su incapacidad de lidiar con ellos perjudicando así a los nacionales en situación de pobreza.

Tipo 6: Discursos abiertamente racistas en contra de los inmigrantes (Torre, 2019). Este autor encuentra este discurso en comentarios acerca de la población haitiana en México, esto es, una población de origen afrocaribeño.
Tipo 7: Discursos que consideran como "otros" a los nacionales que apoyan a los inmigrantes (Kreis, 2017). En este tipo de discursos sus autores se suelen presentar como representativos del grupo nacional, a diferencia de aquellos que apoyan a los inmigrantes. Estos discursos manifiestan las divisiones internas, principalmente en el ámbito ideológico, que existe entre la población del país receptor.

Tipo 8: Discursos que culpan a los medios de comunicación de apoyar a los inmigrantes (Kreis, 2017). Se suele acusar a los medios de comunicación de ocultar información que muestre en su verdadera dimensión los agravios y delitos cometidos por los inmigrantes.

Una característica común en la mayoría de estos discursos es que se suelen presentar acompañados de evidencia anecdótica en primera o tercera persona, aunque solo unos pocos citan fuentes (muchas veces de dudosa procedencia) para sustentar sus opiniones (Torre, 2019).

\section{Método}

El presente estudio es lo que en el lenguaje de los estudios de Internet se denomina "Análisis de contenido de un corpus de datos encontrado en línea" (Hine, 2015). Las preguntas de investigación que se intentan responder son: ¿cuáles son las principales ideas xenófobas hacia los inmigrantes venezolanos que exteriorizan los internautas peruanos en Twitter?; y ¿cómo son confrontadas aquellas ideas 
xenófobas expresadas por internautas peruanos en Twitter?

Por otro lado, y como es común en un campo multidisciplinario como este, la metodología que se adoptará en este estudio es mixta, con una predominancia del análisis cualitativo sobre el análisis cuantitativo, denominada CUAL-CUAN por Hernández et al. (2014). Así, la primera fase del estudio será de tipo cuantitativo y en ella se usarán métodos computacionales para extraer grandes cantidades de información de Internet (en este caso, tuits) y para hacer un análisis descriptivo de las principales categorías de términos que aparecen en la información extraída, de modo que se puedan generar hipótesis provisionales sobre el tipo de ideas expresadas hacia los inmigrantes venezolanos en Twitter. Una vez propuestas estas hipótesis provisionales, se extraerán tuits de las bases de datos que contengan las categorías de términos más usados para así poder analizar los significados de estos mensajes en mayor profundidad y ver como son usados por los internautas peruanos.

E1 uso de un enfoque como este se justifica debido a las grandes cantidades de información que se pueden extraer de Internet, lo que por un lado, abre la oportunidad de poder analizar cantidades de datos que antes no estaban disponibles por métodos tradicionales, y por el otro, genera la imposibilidad de seleccionarlos y analizarlos de manera manual, por lo que el uso de técnicas computacionales para la

${ }^{2}$ También existen tuits publicados de manera privada, los cuales no pueden ser vistos por otros usuarios y tampoco son utilizables para investigaciones. Estos tuits solo son recolección y tratamiento se hace indispensable (Hine, 2015).

Por otro lado, tres puntos que requieren mayor explicación son la elección de Twitter como sitio estratégico de estudio, la técnica de extracción de información (el web-scraping) y el tratamiento que se le dará a la información antes del análisis cuantitativo y cualitativo.

En primer lugar, uno de los sitios web preferidos para aplicar web-scraping es Twitter debido a que permite a cualquier usuario acceder a los tuits que son publicados de manera abierta ${ }^{2}$ (Serfass et al., 2017). Tuit (del inglés tweet) es el nombre que se usa para denominar a las publicaciones de los usuarios en esta plataforma, la cual tiene ciertas características que influyen en el tipo de mensajes que se pueden publicar (Alonso, 2018; Kursuncu et al., 2019). La primera de ellas es que todo tuit está limitado a 280 caracteres (que pueden ir acompañados de elementos audiovisuales), lo que fomenta el uso de abreviaturas no convencionales, faltas de ortografía y errores gramaticales intencionales. Otra característica es el uso de hashtags que son pedazos de textos precedidos por el símbolo “\#” (\#palabra) que inicialmente están pensados para ayudar en la categorización de los temas de los tuits, de modo que los usuarios puedan encontrarlos (Alonso, 2018) pero, según algunos autores (Kreis, 2017; Nguyen, 2015), también se utilizan para significar membresía en un grupo, permitiendo a los usuarios buscar temas

visibles para los contactos de quien los publica durante el tiempo que el usuario marque la opción "proteger mis tuits" en su configuración de privacidad. 
que les interesan y encontrar otros usuarios que comparten sus preferencias. Esta capacidad de afiliar usuarios, unida al anonimato que permite Twitter, brinda a los usuarios espacio para ocultar aspectos de sus identidades fuera de línea con lo que pueden participar de manera selectiva en temas y comunidades que dan forma a sus identidades de acuerdo con sus ideales individuales (Nguyen, 2015). Twitter también brinda la posibilidad de publicar retuits (del inglés retweet) que consisten en tuits escritos y publicados por un usuario y que otros comparten manteniendo siempre la autoría original del tuit. Finalmente, Twitter permite hacer menciones ("etiquetados") a otros usuarios a través de escribir su dirección (@usuario) en el texto de un tuit. Este etiquetado permite lanzar un mensaje directo a otros usuarios, con lo que se atrae su atención o se solicita su opinión.

Por otro lado, los tuits públicos (aquellos abiertos a la observación de todos los usuarios) cumplen con ciertas potencialidades que investigadores como Torre (2019) consideran ventajosas para el estudio de los discursos públicos: 1) incluyen intervenciones tanto politizadas como no politizadas; 2) dado que no es necesario dar nombres verdaderos, las personas se expresan de forma más libre y honesta al no darse las determinaciones de las conversaciones cara a cara; 3) los tuits públicos son de acceso abierto a los usuarios que pueden leerlos, citarlos (publicarlos como retuits), darles "me gusta" o responder a ellos; y 4) si no los eliminan, los tuits permanecen publicados durante el tiempo que exista la cuenta que los creó, lo que permite la realización de estudios longitudinales. Además, al extraer información de Twitter no solo se accede a los tuits, sino también a un conjunto de metadatos ${ }^{3}$ sobre ellos que permiten llevar a cabo el trabajo de selección de los tuits de acuerdo con los objetivos de investigación de quien extraiga los datos (Kursuncu et al., 2019).

Asimismo, Twitter tiene una característica que limita su utilidad como sitio estratégico de investigación. De modo que, al igual que lo expresado por Miller et al. (2017) para Reino Unido y por van der Vyver (2019) para Sudáfrica, Twitter no es una muestra representativa de la sociedad peruana pues su número de usuarios solo llega hasta los 2.8 millones (Redacción Andina, 2020). Esto es un problema desde el punto de vista cuantitativo, pues una muestra basada en esta población probablemente no podrá arrojar resultados que describan al total de la sociedad peruana, sin embargo, no es necesariamente un problema para la investigación cualitativa, puesto que la disponibilidad de ideas expresadas en los tuits permite hacer un análisis a profundidad de su contenido.

En segundo lugar, el web-scraping es el uso de programas (ya sean aplicaciones o líneas de código) para la extracción de grandes cantidades de información que están disponibles en sitios web. En esta investigación, siguiendo la metodología de

\footnotetext{
${ }^{3}$ Los metadatos de los tuits se pueden revisar en el enlace: https://developer.twitter.com/en/docs/twitter-api/v1/datadictionary/overview/tweet-object
}

Global Media Journal México, 18(34), 160-184, enero - junio 2021. 
Miller et al. (2017) y de Nguyen (2015), se ha usado una API de Twitter escrita por el autor en el lenguaje de programación R. Pero la información extraída mediante el web-scraping no se constituye por datos "en bruto" en el sentido de que se recoja la información de Internet sin un ordenamiento previo, por el contrario, tal como afirman Marres y Weltevrede (2013), el web-scraping representa "una forma de extraer campos específicos o elementos de datos de páginas en la web y otras fuentes de Internet, convirtiendo los datos en línea en conjuntos de datos útiles y bien ordenados" (p. 316). Esto es así porque la extracción se hace basándose en palabras clave respecto de las cuales el programa genera tablas con datos adicionales (metadatos). Además, en el presente estudio se sigue la metodología de Nguyen (2015) que consiste en recoger la información sistemáticamente durante intervalos de tiempo (en este caso con intervalos semanales desde el 15 de agosto hasta el 10 de octubre de 2020), para construir un corpus diacrónico que permita examinar la información en diversos episodios. Pero el webscraping no está exento de problemas y el estudio de Miller et al. (2015) nos señala dos: el conjunto de datos inicial puede contener información que es irrelevante para el objeto de estudio y a veces está información es abundante; y se puede pasar por alto información que es relevante para el objeto de estudio debido a la omisión de algunas palabras clave. El primer error se soluciona haciendo procesos de limpieza de datos y el segundo es una limitación humana en el uso de herramientas computacionales.

Así, las palabras clave que se usaron en la extracción de información fueron 16 términos de búsqueda que se refieren a la población venezolana tanto de manera neutra, como de manera coloquial/despectiva. Posteriormente, los resultados de estas búsquedas se agrupan con referencia al término clave principal (grupo). El detalle se ve en la Tabla 1.

\section{Tabla 1}

Términos de búsqueda y grupos

\begin{tabular}{ll}
\hline Términos de búsqueda & Grupos \\
\hline Venezolanos Perú & \\
Venezolanos Lima & \\
Venezolano Perú & \\
Venezolano Lima & Venezolano \\
Venecos Perú & \\
Venecos Lima & \\
Veneco Perú & \\
Veneco Lima & \\
\hline Venezolanas Perú & \\
Venezolanas Lima & \\
Venezolana Perú & \\
Venezolana Lima & \\
Venecas Perú & \\
Venecas Lima & \\
Veneca Perú & \\
Veneca Lima & \\
\hline
\end{tabular}

Esta división de los datos en dos grandes grupos de acuerdo con el género sirve para comparar el tipo de discurso xenófobo/racista que se dirige hacia las mujeres venezolanas del discurso xenófobo/racista que se dirige hacia los varones y la población venezolana en general, puesto que en castellano el plural terminado en "o" engloba tanto a la población masculina como al total de la población.

Finalmente, en el tratamiento previo al análisis que se le dio a la información extraída se han seguido las estrategias de Serfass et al. (2017),

Global Media Journal México, 18(34), 160-184, enero - junio 2021. 
Nguyen (2015) y Kreis (2017). Este proceso de limpieza de datos implicó los siguientes pasos: eliminar tuits que sean de publicidad o comunicación corporativa, para ello se retiraron los tuits provenientes de cuentas que tengan más de 10 mil seguidores y los tuits que provengan de aplicaciones de terceros; conservar solo los tuits que estén escritos en español; y conservar los tuits que provengan de
Perú o que no tengan marcado el país de procedencia ${ }^{4}$. Además de ello, se retiraron los tuits duplicados, esto es, tuits que tengan los mismos valores en las variables referentes a fecha de creación, creador, y texto del tuit. La diferencia entre la cantidad de datos en bruto y la cantidad de datos después del filtrado se puede ver en la Tabla 2.

\section{Tabla 2}

Cantidad de tuits por término de búsqueda y grupo

\begin{tabular}{lcccc}
\hline $\begin{array}{c}\text { Términos } \\
\text { de búsqueda }\end{array}$ & Tuits en bruto & Grupos & $\begin{array}{c}\text { Tuits agrupados } \\
\text { en bruto }\end{array}$ & $\begin{array}{c}\text { Tuits agrupados } \\
\text { tras filtrado }\end{array}$ \\
\hline Venezolanos Perú & 5,349 & & & \\
Venezolanos Lima & 969 & & & \\
Venezolano Perú & 1,934 & & & 5,694 \\
Venezolano Lima & 1,009 & Venezolano & 9,895 & \\
Venecos Perú & 349 & & & \\
Venecos Lima & 50 & & & \\
Veneco Perú & 208 & & & \\
Veneco Lima & 27 & & & \\
\hline Venezolanas Perú & 545 & & \\
Venezolanas Lima & 65 & & & \\
Venezolana Perú & 1,361 & & \\
Venezolana Lima & 327 & Venezolana & & \\
Venecas Perú & 38 & & & \\
Venecas Lima & 5 & & & \\
Veneca Perú & 73 & & \\
Veneca Lima & 9 & & & \\
\hline Total & 12,318 & & & \\
\hline
\end{tabular}

El análisis de estos tuits, siguiendo un diseño mixto, se hará en dos fases. En primer lugar, se analizará cada grupo por separado para establecer cuáles son las categorías de términos usadas con más frecuencia

${ }^{4}$ Twitter no configura por defecto que los tuits señalen el país del que provienen, por lo que esta información solo estará disponible si el usuario configura que la aplicación guarde esta información. Si no lo hace, aquella información queda vacía. Por lo que si una persona activa en cada uno de estos grupos. Debido a que resulta prácticamente imposible hacer esta primera parte del análisis de manera manual, se usará el lenguaje de programación R para procesar el texto y encontrar las

esa opción y el metadato de su tuit dice que fue enviado desde Perú, entonces se puede tener seguridad de ello, pero si no hay información, no se puede saber con exactitud de donde proviene el tuit. 
frecuencias de las categorías de términos más usadas y ordenarlas en tablas.

En segundo lugar, una vez identificadas las categorías de términos más utilizados, se seleccionarán las 15 más usadas de cada base y se elegirán los tuits que contengan estos términos de acuerdo con el siguiente criterio: que sean los tuits con mayor cantidad de "me gusta" y retuits dentro de la base de datos. Una vez seleccionados, se procederá a analizar cualitativamente el contenido de estos tuits basándonos en la tipología de discursos xenófobos desarrollada en la sección anterior.

\section{Resultados de la fase cuantitativa}

Una forma gráfica de ver cuáles son las categorías más utilizadas con respecto a una población es mediante un treemap, el cual consiste en un tipo especial de visualización que ordena los datos en rectángulos de distinto tamaño de acuerdo con su frecuencia. En este caso se han generado dos treemap (Figuras 1 y 2), cada uno con las 40 categorías más frecuentes para cada grupo -Venezolana y Venezolano- y la cantidad de veces que aparece mencionada.

\section{Figura 1}

Treemap para el grupo "Venezolana"

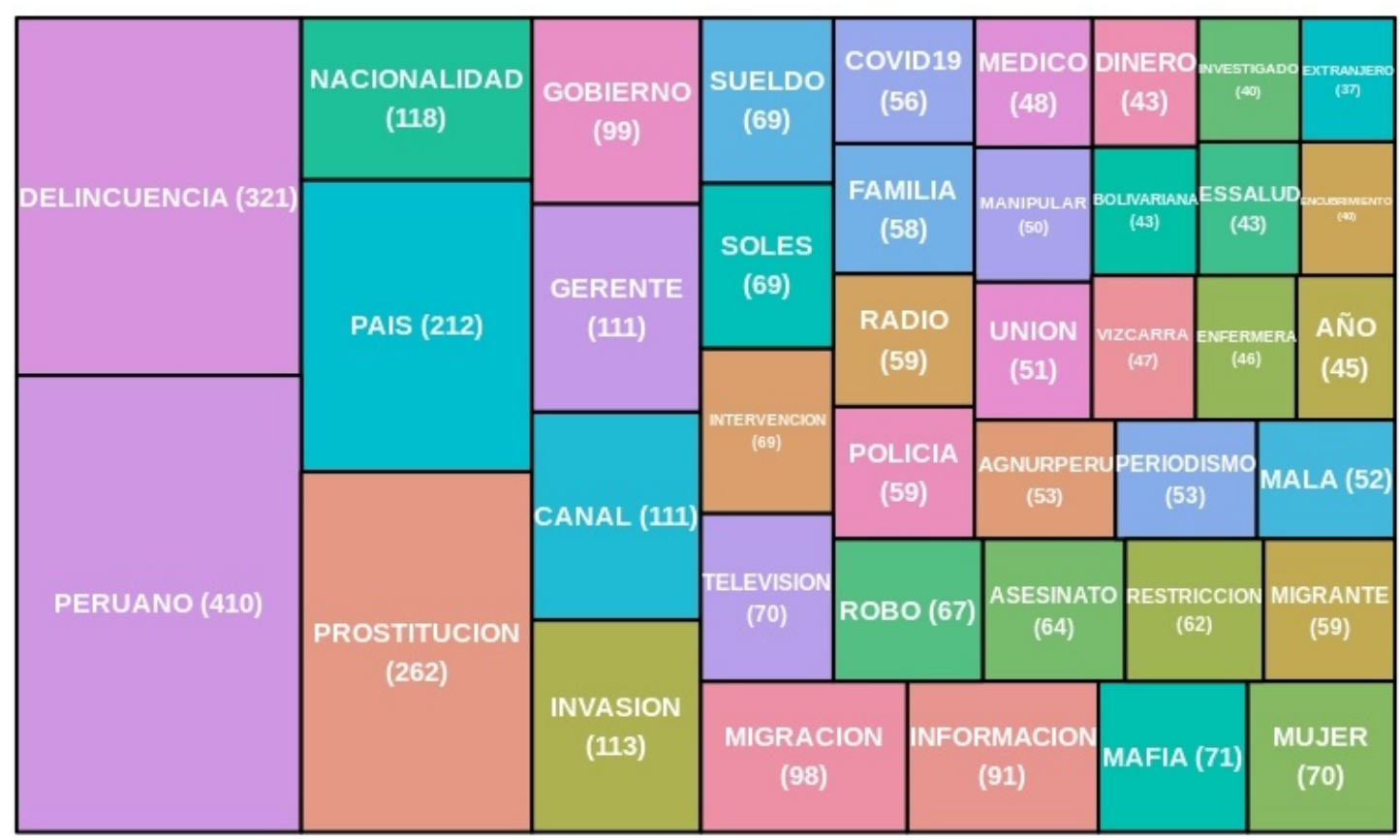

Global Media Journal México, 18(34), 160-184, enero - junio 2021. 


\section{Figura 2}

Treemap para el grupo "Venezolano"

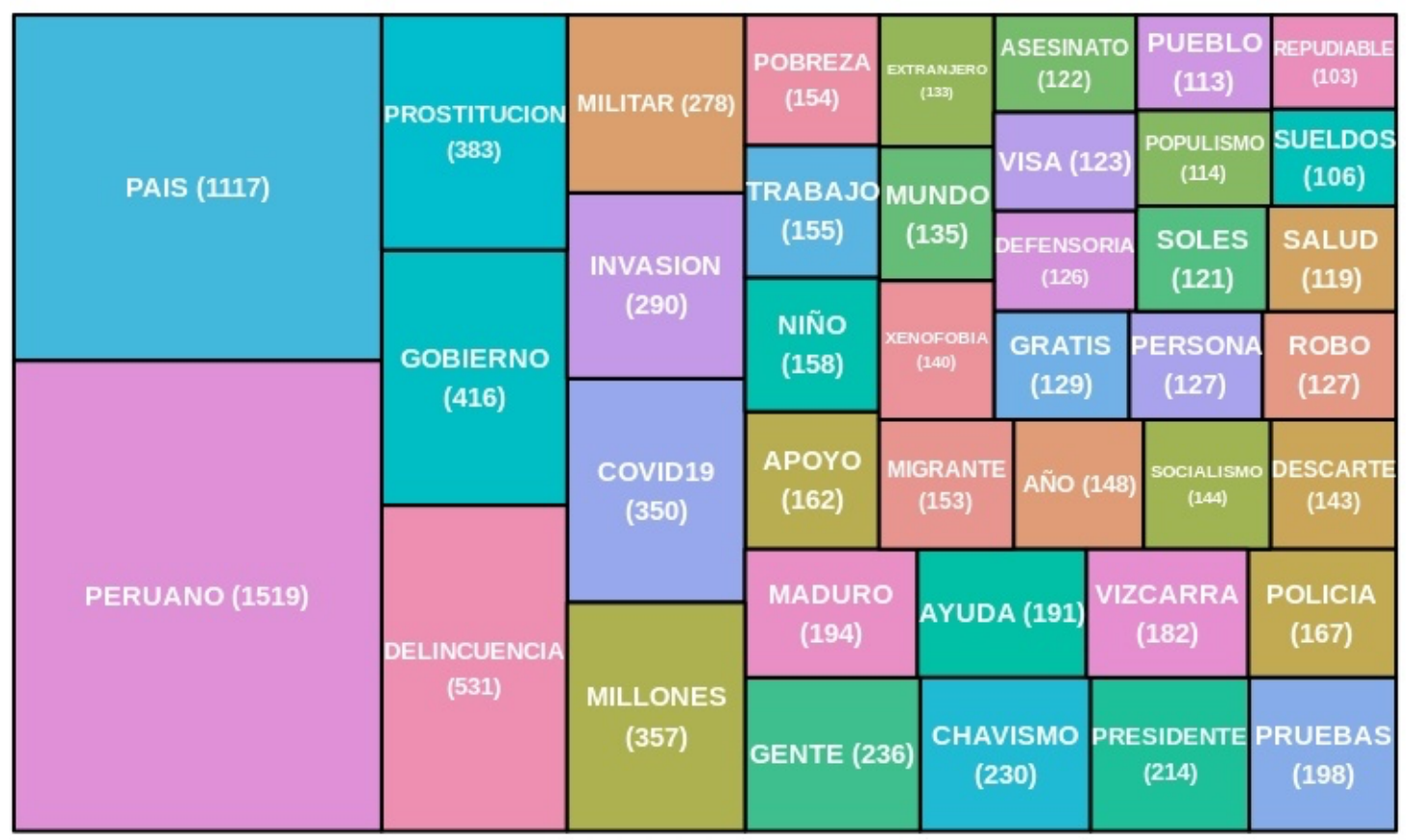

A primera vista podemos ver algunas coincidencias en ambos treemap. La categoría principal (y, por ende, la que tiene el rectángulo más grande) es "peruano". También están entre las de mayor frecuencia las categorías "delincuencia" y "país". Una sutil diferencia entre ambos treemap es la categoría "prostitución", que ocupa un espacio considerable en el gráfico para el grupo Venezolana, pero no así en el gráfico para el grupo Venezolano. Estas diferencias se pueden ver mejor en la Tabla 3 que muestra las 15 categorías más frecuentes en cada grupo y sus frecuencias relativas ${ }^{5}$.

De las cinco categorías más frecuentes, cuatro de ellas se repiten en ambos grupos, de modo

5 Se usan frecuencias relativas en vez de frecuencias absolutas debido a que el grupo Venezolano contiene aproximadamente cuatro veces la cantidad de tuits que el grupo Venezolana, por lo que la comparación directa se que la diferencia radica en las categorías "gobierno" y "nacionalidad" que se encuentran en los grupos Venezolano y Venezolana, respectivamente. Otra diferencia radica en el peso relativo de la categoría "prostitución” en ambos grupos. Así, mientras en el grupo Venezolano su frecuencia relativa es de $5.89 \%$, en el grupo Venezolana esta frecuencia representa casi el doble, 11.77\%. Esto nos da una idea de que las referencias hacia la prostitución son mayores cuando se habla de las mujeres venezolanas en comparación a cuando se habla de los varones venezolanos o de la población venezolana en general. Sin embargo, para profundizar más en la comprensión de estas diferencias, es necesario

hace difícil. Además, las frecuencias relativas se han calculado dividiendo la frecuencia absoluta de la aparición de cada categoría entre la suma de las frecuencias de las 15 categorías consideradas. 
analizar los tuits de ambas bases que contengan algunos de los términos de las categorías presentes en la Tabla 3, tarea a la que procederemos a continuación.

\section{Tabla 3}

Frecuencias relativas de las 15 categorías de términos más frecuentes en cada grupo

\begin{tabular}{lclc}
\hline \multicolumn{2}{c}{ Venezolano } & \multicolumn{2}{c}{ Venezolana } \\
\hline \multicolumn{1}{c}{ Palabras } & $\begin{array}{c}\text { Frecuencia } \\
\text { relativa }\end{array}$ & \multicolumn{1}{c}{ Palabras } & $\begin{array}{c}\text { Frecuencia } \\
\text { relativa }\end{array}$ \\
\hline Peruano & $23.6 \%$ & Peruano & $18.4 \%$ \\
País & $17.8 \%$ & Delincuencia & $14.4 \%$ \\
Delincuencia & $8.2 \%$ & Prostitución & $11.8 \%$ \\
Gobierno & $6.4 \%$ & País & $9.5 \%$ \\
Prostitución & $5.9 \%$ & Nacionalidad & $5.3 \%$ \\
Millones & $5.5 \%$ & Invasión & $5.1 \%$ \\
Covid19 & $5.4 \%$ & Gerente & $5.0 \%$ \\
Invasión & $4.5 \%$ & Canal & $5.0 \%$ \\
Militar & $4.3 \%$ & Gobierno & $4.5 \%$ \\
Gente & $3.6 \%$ & Migración & $4.4 \%$ \\
Chavismo & $3.5 \%$ & Información & $4.1 \%$ \\
Presidente & $3.3 \%$ & Mafia & $3.2 \%$ \\
Pruebas & $3.0 \%$ & Televisión & $3.1 \%$ \\
Maduro & $3.0 \%$ & Mujer & $3.1 \%$ \\
Ayuda & $3.0 \%$ & Sueldo & $3.1 \%$ \\
\hline
\end{tabular}

\section{Resultados de la fase cualitativa}

La presentación de resultados de la fase cualitativa se divide en dos secciones; la primera de ellas analiza los discursos xenófobos/racistas hacia los inmigrantes mientras que la segunda sección analiza los discursos que se esgrimen en respuesta a las expresiones de xenofobia y racismo, experimentadas tanto de manera virtual como cara-a-cara.

\section{Discursos xenófobos y/o racistas hacia los inmigrantes}


primera de ellas es a través de discursos de denuncia pública, en los cuales se enuncia de manera exagerada los crímenes de los que se acusa a los inmigrantes y se etiqueta a ciertas autoridades o personajes públicos para que tomen cartas en el asunto. He aquí algunos ejemplos:

@SamuelAldanaV @George_Forsyth
@carlosscull No sé si sea 80\% pero la
delincuencia en lima aumentó
exponencialmente desde la llegada de
venezolanos, mucho más feroces q los
delincuentes peruanos, sorry pero eso lo vio
todo el Perú.

@jguaido Oiga qué pasa con sus compatriotas!!! En el Perú han creado mafias, prostituyen a sus mujeres, matan a sueldo, roban, etc... iijLos peruanos estamos hartos de la delincuencia venezolana!!!

@PoliciaPeru@atvmasnoticias@exitosape @RPPNoticias@@peru21noticias @elcomercio_peru@DiarioElPeruano @canalN_@RadioNacionalFM @ExpresoPeru@elpopular_pe Deberían DEPORTAR a todos los delincuentes Venezolanos ¿porqué siguen en Perú? Siguen matando a nuestros hermanos y el gobierno se mufa de todo nuestro dolor ¿hasta cuándo? @pancho88948814

@UNICEFperu

@aCNURamericas

venezolanas han venido, gente que da el culo para darle de comer al marido, mujeres putas, descuartizadores, larguense de mi pais sarta de delincuentes, el marido manda a la mujer a dar el culo para comer rico.

Como se puede ver, en estos mensajes se etiqueta a medios de comunicación, a políticos (George Forsyth), e instituciones (la Policía Nacional del Perú) del país receptor, además de autoridades del país de origen de los inmigrantes como Juan Guaidó o Carlos Scull. El etiquetado a estos medios, instituciones o personajes sirve tanto para ponerlos al corriente de lo que el emisor del mensaje quiere expresar como para que cualquier otro usuario que busque información sobre alguno de estos medios, instituciones o personajes pueda encontrar el tuit de denuncia en sus resultados de búsqueda, por lo que amplía el alcance del mensaje.

Por otro parte, un hecho importante en dos de estos tuits es que en ellos se puede apreciar un estereotipo xenófobo que existe hacia la población inmigrante; el estereotipo que caracteriza a los varones (o la población en general) como delincuentes y a las mujeres como prostitutas. Veremos este estereotipo repetirse a lo largo de muchos tuits citados en la presente investigación.

La segunda forma en que se presentan estos discursos es como pretexto para atacar rivales políticos, tal como se ve en el siguiente tuit en el que se señala como responsable político al expresidente

Global Media Journal México, 18(34), 160-184, enero - junio 2021. 
Kuczynski. En este sentido, la protesta contra los crímenes cometidos por inmigrantes se convierte también en una protesta política contra tendencias que no rechazan a los inmigrantes.

@PoliciaPeru@diariocorreo@exitosape @noticias_tvperu@@Agencia_Andina @larepublica_pe@Latina_Noticias @atvmasnoticias@@canalN_ @peru21noticias@ExpresoPeru Cada dia venezolanos en páginas policiales, asaltan roban y ocasionan problemas porque no se los expulsa y q nunca más regresen esta Lacra de gentuza solo ha traido problema a nuestro país culpa de PPK culpable a esta gente que ha invadido Perú.

La tercera forma también hace eco de etiquetar a autoridades, pero en este caso con la intención de exigir acciones en contra de la amenaza. Además, en estos mensajes no es necesario expresar que todos los inmigrantes son una amenaza a la seguridad pública, basta con señalar la amenaza existente.

@MartinVizcarraC Presidente Vizcarra cuando pondrás un límite a la migración venezolana sin documentos en Perú, todos los dias entran delincuentes, los que quieran venir a Perú que no tengan antecedentes, que vengan a contribuir, no a empeorar la situación.

Otro tipo de discursos son los de Tipo 4, esto es, discursos que señalan al inmigrante como amenaza a la salud pública. Estos mensajes pueden tomar el mismo patrón encontrado en el tipo anterior, esto es, una denuncia pública que etiqueta a algún medio, personaje o institución.

@Minsa_Peru Me parece fantástico la
información pero seguimos viendo a
motorizados de Rappi y Glovo la mayoría de
nacionalidad venezolana que van de a dos en
motos haciendo delivery (no debería ser así)
y no respetan el distanciamiento de motos en
los semáforos.

En el tuit anterior la xenofobia no es abierta, sino sutil. En el mensaje no se dice que los inmigrantes son los únicos que no respetan el distanciamiento social (y, por ende, dispersan el COVID-19) sino que se les usa como ejemplo de esa mala práctica.

En proporción similar aparecen los discursos de Tipo 5, aquellos que exigen tratamiento favorable al nacional por encima del extranjero. Estos tuits por lo general no son de denuncia, pero repiten la estrategia discursiva de etiquetar medios, personajes o instituciones para aumentar el alcance de su mensaje. He aquí dos ejemplos:

@KateTrendyNow@Gestionpe La sinvergüenza Faccim sale a pedir dinero a nuestro gobierno y dice que no ayudamos a Venecos ya bastante hemos hecho recibiendo tanto Veneco ladrones asesinos mendigos drogadictos y toda la Lacra Veneca. Que le pida a Maduro o que se los lleve a su país, es una carga para Peru. 
@peru2 Inoticias El gobierno da prioridad a sus ciudadanos peruanos.

@ACNURamericas@embajadave_pe dan un bono a todo migrante.Yq@Minsa_Peru @Rosario_Sasieta hagan una campaña d uso de anticonceptivos ante la pandemia. Han visto la cantidad de venezolanas embarazadas y bebés pidiendo limosna.

El tono de ambos tuits es opuesto, aunque manifiestan xenofobia. Están contextualizados en la crisis económica generada por las medidas impuestas por el gobierno para frenar la pandemia, lo que generó problemas graves en muchas poblaciones vulnerables, incluida la población inmigrante. En el primero de ellos vemos un tono agresivo en el que se insulta a una activista inmigrante (Paulina Facchin) y se adjetiva a los inmigrantes de maneras muy negativas. Además, se caracteriza a esta población como "una carga para Perú" lo que es un claro ejemplo de aporofobia.

En el segundo tuit vemos un tono menos agresivo, pero se hace una clara diferenciación de hacia quienes debe estar dirigida la ayuda del gobierno peruano. En concordancia con el tono no agresivo del tuit, se sugieren posibles salidas para ayudar a esa población. En este tuit la xenofobia es velada, y se puede encontrar en el recurso discursivo de culpar a la gran cantidad de hijos que se tiene de la situación de pobreza. Junto a ello, la xenofobia también se encuentra en ambos tuits en la separación tajante de a quienes tiene que ayudar el Estado
Peruano, la cual conlleva la idea implícita de que únicamente los peruanos contribuyen a las arcas del Estado y por ello sus ayudas les corresponden por derecho, ignorando el hecho de que los ingresos del Estado provienen de todas las actividades económicas del país, sin importar la nacionalidad de quienes las ejerzan.

Otros tipos de discursos menos frecuentes ${ }^{6}$ son los de Tipo 2, 6 y 8. En los discursos de Tipo 2, aquellos que señalan al inmigrante como amenaza económica, se apela a los más pobres del país, quienes se ven afectados por la competencia laboral que significa la llegada de inmigrantes dispuestos a trabajar. He aquí un ejemplo de ello:

@elcomercio_peru En plena crisis LOS VENECOS le quitan el trabajo a los más pobres, a nuestros compatriotas que menos oportunidades tienen por culpa de la CURRUPCION, hasta cuando.

En los discursos de Tipo 8, aquellos que culpan a los medios de comunicación de apoyar a los inmigrantes, el recurso discursivo principalmente utilizado es culpar a los medios de ocultar crímenes que estarían cometiendo los inmigrantes u ocultar la nacionalidad de los autores de ciertos crímenes. Esto se ve en el mensaje siguiente, en el que además se hace evidente la diferencia de estereotipos de género adjudicados a la población inmigrante:

${ }^{6}$ Los discursos de Tipo 1, y 7 son menos frecuentes, por lo cual no serán analizados.

Global Media Journal México, 18(34), 160-184, enero - junio 2021. 
@atvmasnoticias@VertizPamelaPrograma basura que solo da a conocer lo que le conviene, estos delincuentes venezolanos $y$ prostitutas venezolanas deben de largarse del Perú, lo único que generan es inestabilidad en el país, muerte a estos desgraciados.

En los discursos de Tipo 6, son abiertamente racistas; se mencionan los rasgos físicos de los inmigrantes para atribuirles la autoría de crímenes.

\section{@VeroLinaresC@Minsa_Peru EL DELINCUENTE DE SAN MARTIN DE PORRAS ES VENEZOLANO SE NOTA CUANDO SE SACA LA GORRA TIENE RASGOS MORENOS.}

Este tuit reproduce asimismo una idea racista persistente en nuestra sociedad, esto es, la idea de que las personas afrodescendientes se dedican principalmente a la delincuencia. En este sentido, muchos miembros de la población inmigrante podrían estar sufriendo de xenofobia a causa de su origen extranjero, y de racismo a causa de su ascendencia afrocaribeña.

Por otro lado, se encontraron discursos que no encajaban en los Tipos antes descritos, muchos de ellos eran una combinación de dos o más Tipos de discursos y otros eran completamente diferentes a los mencionados hasta ahora. Entre los discursos que combinan algunos de los tipos anteriores, el siguiente tuit muestra una combinación de los Tipos 5 y 6; este discurso exige prioridad para los nacionales a la vez que insulta racialmente a los inmigrantes.

@peru21noticias Primero los venezolanos no tienen derecho a pedir nada, que lo hagan en su pais, la mayoría son malagradecidos, ningún país ayuda cómo Perú, solo vienen gente basura y los mas pobre de negrozuela sólo a joder, no dicen los crímenes que cometen su gente, luchen por su pais.

También hay tuit que combina los Tipos 2 y 4, esto es, que ve a la inmigración como una amenaza tanto económica como sanitaria.

La invasión masiva venezolana, pauperizó la Salud, vivienda y empleo de los peruanos más pobres... Llegaron miles con enfermedades crónicas como el Sida... Con casi dos millones de venezolanos en Perú, las esquinas y calles se llenaron de ambulantes, prostitutas y delincuentes.

Este tuit es interesante pues en el mismo, el mensaje se discurre desde un problema sanitario imaginario (llegada del SIDA) hacia un oficio que, como se vio en el análisis precedente, se atribuye a las mujeres inmigrantes (la prostitución). Vemos así que se cumple la idea de relacionar la amenaza a la salud pública con la práctica de oficios supuestamente insalubres como la prostitución.

Con respecto a los tipos de discursos distintos a los hallados en la literatura, estos se describen a continuación.

Global Media Journal México, 18(34), 160-184, enero - junio 2021. 
Tipo 9: Discursos que ven a los inmigrantes como causantes de todos los problemas sociales. En estos discursos se resalta de manera muy general que son los inmigrantes los que causan los problemas sociales, tal como se ve en el siguiente tuit:

Los países mismos buscan su destrucción gracias a las malditas ONG acogen terroristas, delincuentes, asesinos etc, al igual que acá con un millón de venezolanos sin filtro han hecho casi imposible vivir en el Perú.

Además, este tuit recurre a culpar a las "ONG que acogen terroristas", el cual es un recurso discursivo muy usado por personas ideológicamente inclinadas hacia la derecha. También hay discursos más sutiles, como en el siguiente tuit:

@1Ricper Eso es precisamente lo que se viene sino le damos un cambio drástico a esta situación, la desgracia de este gobierno no está acercando a la realidad venezolana y se establecerá cuando en el Perú se elija a un venezolano.

En este tuit no se culpa directamente a los inmigrantes de todos los problemas sociales, pero se les ve como una amenaza que puede empeorarlo todo, lo que en términos del autor del tuit consistiría en acercarnos a la "realidad venezolana".

Tipo 10: Discursos que rechazan la integración de los inmigrantes. Este tipo de discursos manifiestan dos intenciones; mantener una barrera de separación entre la población inmigrante y la población nacional; o criticar acciones que crucen esa barrera.

El primer tipo de intención ha sido identificado en tuits que hablan sobre política. En estos tuits se enuncia la imposibilidad o prohibición de que un inmigrante participe de alguna manera en la política del país anfitrión. Esto se puede ver en los dos tuits siguientes:

El "veneco" asi tiene a La Victoria. Ya podemos imaginarnos como tendría al Perú. Ha nacido en Caracas, Venezuela. No puede ser presidente de nuestro pais. "Art. 110 de nuestra Constitución señala que para ser Presidente del Perú se requiere ser peruano de nacimiento".

Podemos Peru: Cecilia Garcia, Daniel Urresti y Jose Luna, tiene su youtuber venezolana preferida, $q$ rebota y aplaude sus intervenciones en política en su canal "mi canal Peru" donde tb critica al gobierno. Solo Recordarle a la dama, q un refugiado NO puede intervenir en política.

El primer tuit se contextualiza en una crítica al gobierno municipal de George Forsyth en el distrito de La Victoria, y para criticarlo se le denomina de manera despectiva con respecto a su lugar de nacimiento. Efectivamente, Forsyth nació en Venezuela debido a que su padre era diplomático peruano en ese país, y sin embargo, ello no impide 
considerarlo peruano de nacimiento de manera legal (Aldazabal, 2019).

En el segundo tuit se resalta que un extranjero no puede participar en alusión a una inmigrante que opina sobre el país a través de su canal de YouTube. Así, la prohibición de participar en política se extiende hasta el ámbito discursivo, prohibiéndole a los inmigrantes incluso opinar sobre la realidad del país que habitan.

El segundo tipo de intención justifica su crítica a las interacciones que se puedan dar entre inmigrantes y nacionales en base a los supuestos crímenes o acciones negativas que han cometido los miembros de la población inmigrante.

@NoireDoom Acá en perú, los venecos han ocasionado desastres, han hecho crímenes horribles, y lo peor es que el gobierno ha permitido que entren así nomás, con familia e incluso a mujeres embarazadas. Lo peor de todo es que peruanos se están enamorando de venecos y ya están teniendo hijos.

El uso de una frase como "lo peor de todo" para referirse a la creación de lazos familiares entre inmigrantes y nacionales apunta a que la integración de los inmigrantes en la sociedad nacional es un resultado no deseado.

Tipo 11: Discursos que usan a los inmigrantes para atacar a un bando político opuesto. Estos discursos son diversos y dependen del bando político al que se esté atacando. Así, en el siguiente tuit se usa el ejemplo de la crisis venezolana para ejemplificar lo que sería el resultado de aplicar

políticas de izquierda y a su vez culpar a este tipo de políticas de la supuesta tendencia al crimen de los venezolanos.

\begin{tabular}{|c|c|}
\hline @JuanCar75848016 & @peru21noticic \\
\hline @oppenheimera & @washington \\
\hline (a)l_pais & @ComunicaTacr \\
\hline @elcomercio_peru & @NoticiasON \\
\hline Almagro_OEA2015 & CNNEE Jajaj \\
\hline He ahi las consecuer & s del socialismo \\
\hline comunismo, cría la & cría chicos c \\
\hline que quieren & 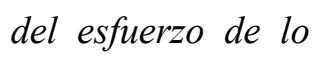 \\
\hline ijeno como príncip & y se victim \\
\hline has preguntado por & no quieren a \\
\hline$D$ & VCUENTES... \\
\hline
\end{tabular}

Tipo 12: Discursos que rechazan cualquier queja de los inmigrantes. La idea detrás de estos tipos de discursos es que los inmigrantes no tienen derecho a quejarse de nada. Esto se puede ver en los siguientes tuits:

@FranciaAndrade

@Defensoria_Peru

(aperu21noticias

Entonces largate pues cotorra nadie los invitó a venir y las prostitutas venezolanas acá tienen al menos un pan para vivir, allá no tienen ni para limpiarse el culo. Entiendes o a la mala entiendes? Vayanse nadie los quiere acá

Global Media Journal México, 18(34), 160-184, enero - junio 2021. 
Este tuit se contextualiza en una queja de una inmigrante sobre el ataque con ácido en el trasero del que fue víctima una compatriota suya. Sin embargo, la respuesta a esta queja fue violenta y no tuvo ningún tipo de autocrítica por el ataque cometido contra la inmigrante. Este tipo de tuits pueden considerarse como una versión extrema del Tipo 5, de hecho, Alonso (2018) describe para los casos italiano, francés y británico como la lógica de la primacía de los nacionales (aquellos que pertenecen al "pueblo") se relaciona con la lógica que les niega cualquier derecho a los inmigrantes, lo cual tiene como consecuencia la deshumanización de la figura del inmigrante, a quien se considera imposibilitado para quejarse y obligado a aguantar o irse del país.

\section{Discursos de respuesta a la xenofobia/racismo}

Este tipo de discursos pueden ser divididos en dos grandes grupos: Discursos xenófobos/racistas y discursos que critican la xenofobia/racismo.

Con respecto al primer grupo, los discursos xenófobos/racistas pueden a su vez ser divididos en dos tipos según sean respuestas directas a algún ataque discursivo xenófobo/racista o comentarios espontáneos que expresan los estereotipos que tenían los inmigrantes antes de llegar al país receptor o que desarrollaron durante su estancia en el mismo.

Tipo 13: Discursos xenófobos/racistas en respuesta directa a algún ataque discursivo xenófobo/racista de nacionales en contra de inmigrantes. Este tipo de mensajes varían de acuerdo con el ataque previo. Así, en los dos primeros casos se hace referencia a una supuesta inferioridad estética de los nacionales frente a los inmigrantes.

@ALMaximo6@@leonardoadriam @ colinarriba Las putas venezolanas son tan putas como las de tú país, pero más bonitas (hechas con amor) jajaja y los delincuentes que llegaron a Perú fue porque se dieron cuenta que allá no hay autoridades firmes y se fueron a hacer lo que les dió la gana. Es decir, eres bruto más del montón.

Peruano gafo, en Perú ya había delincuentes idiota... Tú país es la cuna de la delincuencia ahora le vas a echar la culpa a los Venezolanos? PERUANO FEO.

En el primer tuit esta inferioridad se expresa en la preferencia por prostitutas inmigrantes en vez de prostitutas nacionales y en el segundo se usa como insulto en respuesta a la común acusación de delincuencia hacia los inmigrantes.

Otros tuits no hacen referencia a una situación específica en las plataformas virtuales, sino al contexto general de haber experimentado xenofobia o racismo en el país receptor, tal como se ve en los tuits siguientes:

¿Ustedes por qué creen que más de 100 mil venezolanos han huido de regreso a su país en los últimos 3 meses? ¿Por que está una dictadura? No, porque se dieron cuenta que la vida en los países del cartel de Lima es un un infierno.

Global Media Journal México, 18(34), 160-184, enero - junio 2021. 
Soy venezolano y tengo un top 3 de países a los que hay que anotar en una lista para guardarles factura: Perú, Ecuador $y$ Trinidad y Tobago. Si se me escapa uno, bienvenido el aporte.

Como se puede ver en estos tuits, el discurso de ambos manifiesta una idea de resentimiento hacia Perú y otros países de la región, un hecho que podría generar problemas de adaptación y convivencia en el corto o mediano plazo.

Tipo 14: Discursos espontáneos que expresan los estereotipos que tenían los inmigrantes antes de llegar al país receptor o que desarrollaron durante su estancia en el mismo. Estos discursos en general dependen de la idiosincrasia del país de origen de los inmigrantes, por lo que su análisis a profundidad escapa del alcance de este estudio. Un ejemplo de este tipo de discurso es el siguiente tuit:

Alguna vez una venezolana que conocí en el mercado me dijo: - Señor Perú es un país muy extraño Yo le dije: - Chama, Perú es un pais para visitar, no para vivir.

Se puede inferir que el autor tenía una idea preconcebida sobre el país de destino, en el cual no son buenas las expectativas de asentarse.

Con respecto a los discursos del segundo grupo, aquellos que critican la xenofobia/racismo, estos se pueden dividir en dos tipos que veremos a continuación.

Tipo 15: Discursos que hacen notar los perjuicios que genera la xenofobia sobre la población inmigrante. Estos discursos son muy variados y dependen del tipo de agravio que la persona denuncie. Así, los dos tuits siguientes hacen notar que el Estado peruano en sus diversas campañas y programas no toma en cuenta a la población inmigrante, ya sea porque hay muchos costos políticos en ello o por alguna forma de exclusión discursiva.

\#Peru y la campaña Lima Aprende:"El Estado peruano no tiene una política porque no la quiere tener...pensar en una estrategia o respuesta integral explícitamente orientada a favorecer a la población \#venezolana sería inviable, pues se trata de un tema politicamente incorrecto..."

Sería lindo que la gente que graba Aprendo en casade@MineduPerudejarade usarla frase "esto es para todos los peruanos y peruanas" puesto que además de venezolanos, hay niños extranjeros de varias nacionalidades estudiando en Perú. Hay muchas maneras de no ser excluyentes.

Otro tipo de tuits hacen notar las dificultades que la xenofobia genera y se deben a las acciones de algunos inmigrantes.

@PedroAVT@oscarabp@George_Forsyth No deberia existir la solidaridad automatica por ser Venezolanos, un gesto loable es desmarcarse de los delincuentes y malos vividores que vinieron a Perú a joder. Desde 
mi punto de vista, deben ser expulsados del Perú o cualquier otro Pais donde esten echando vaina.

@Maria82619343@Psicovivir ¿Y por eso hay que dejarlos pasar ilegalmente y que hagan desastre en otros países? ¿O es qué no recuerdas qué pasó en Perú que entró de todo y después cazaban los venezolanos (honestos o no) gracias a un grupo de malandros que se fue a joder, robar y matar a otros países?

Por último, otros tuits simplemente hacen denotar la xenofobia que existe.

Perú: *Muere un venezolano* Peruanos: "Una rata menos" "que se mueran todos" ¿Odio en Perú? ¡Mentira!

Tipo 16: Discursos que intentan subir la autoestima de la comunidad inmigrante. Estos discursos se usan para intentar sobrepasar la xenofobia al crear consciencia de que el estereotipo xenófobo solo se aplica a una minoría, y que por ende debe ser desoído, tal como se ve en los siguientes tuits:

\footnotetext{
@Rolandoreagno@@Gatubela_0 @colinarriba Comentarios como ese la colocan en el mismo nivel que el peruano que gritó "veneco de mierda", y a Carlos David, la repuesta es ignóralo, son minoría, los buenos somos mas, en Peru y en Venezuela.
}

@LuisOlavarrieta A pesar de la pandemia barbara acá en Perú a mi esposo después de dos años lo contrataron fijo en la empresa. Siendo el único venezolano es demostrar que si se puede. Los buenos somos más. Bendiciones.

Los médicos venezolanos han puesto un pequeño granito de arena para ayudar a la población peruana a salir de ésta crisis sanitaria, núnca debe olvidarse el Perú que no somos delincuentes y que \#losbuenossomosmas.

En el contexto específico del Perú, este tipo de discurso se hizo evidente bajo el eslogan "los buenos somos más", que intentaba hacer notar que no todos los inmigrantes son como los caracteriza el estereotipo xenófobo/racista.

\section{Conclusiones}

Un hecho notorio en la presente investigación es que las dos fases lideraron a resultados similares, lo que aumenta la confiabilidad de este estudio exploratorio, al menos como paso inicial para seguir algunas de las líneas de investigación sugeridas por los hallazgos empíricos aquí encontrados.

Así, respecto a los hallazgos anticipados por la literatura podemos ver que el fenómeno de la xenofobia y racismo hacia los inmigrantes extranjeros en Perú sigue algunos patrones 
identificados en el estudio de este fenómeno en otras realidades. Más específicamente, con excepción de los discursos de Tipo 1 y Tipo 7, los otros seis tipos de discursos identificados en la literatura fueron notorios, siendo más frecuentes los discursos de Tipo 3 , es decir, aquellos que caracterizan al inmigrante como amenaza a la seguridad pública.

Sin embargo, también se identificaron algunos discursos no anticipados por la literatura. El primero de ellos es resultado de la recolección de datos que se llevó a cabo dividiendo las palabras clave por género. Debido a esta diferenciación inicial en las bases de datos pudimos hallar en la fase cuantitativa que uno de los términos más asociados con las inmigrantes hace referencia a la prostitución y este hallazgo fue corroborado en la fase cualitativa en la cual se descubrió una dicotomía de estereotipos negativos, los cuales calificaban a los varones (o a la población inmigrante en general) como delincuentes y a las mujeres como prostitutas.

Además de ello, se encontraron cuatro tipos de discursos xenófobos/racistas, el Tipo 9 (discursos que ven a los inmigrantes como causantes de todos los problemas sociales), el Tipo 10 (discursos que rechazan la integración de los inmigrantes), Tipo 11 (discursos que usan a los inmigrantes para atacar a un bando político opuesto) y Tipo 12 (discursos que rechazan cualquier queja de los inmigrantes). Estos discursos pueden constituirse en objetos de futura investigación sobre la especificidad de los discursos xenófobos/racistas en Perú.

Por el lado de las respuestas contra estos discursos xenófobos/racistas encontramos que estos discursos se dividen en dos grandes grupos. El primero de ellos pertenece a los discursos que responden a la xenofobia/racismo con discursos igualmente xenófobos/racistas. Dentro de este grupo encontramos dos tipos de discursos: Tipo 13 (discursos xenófobos/racistas en respuesta directa a algún ataque discursivo xenófobo/racista de nacionales en contra de inmigrantes) y Tipo 14 (discursos espontáneos que expresan los estereotipos que tenían los inmigrantes antes de llegar al país receptor o que desarrollaron durante su estancia en el mismo). Estos discursos sirven para abrir nuevas rutas de investigación sobre la xenofobia/racismo ya que sirven para hipotetizar que no es un fenómeno en una sola dirección, por el contrario, es un fenómeno que puede tomar diversas direcciones que merecen ser exploradas.

El otro grupo de respuestas corresponde a los discursos que critican la xenofobia/racismo. Dentro de estos grupos se encuentran también dos tipos de discursos: Tipo 15 (discursos que hacen notar los perjuicios que genera la xenofobia sobre la población inmigrante) y Tipo 16 (discursos que intentan subir la autoestima de la comunidad inmigrante). Estos discursos sirven como testimonio de los diversos efectos negativos que tiene la xenofobia/racismo sobre la comunidad inmigrante y cómo intentan superar esta situación desventajosa.

En conclusión, esta investigación ha servido con el mismo propósito de todo estudio exploratorio que es el abrir nuevas rutas de investigación sobre la problemática explorada. 


\section{Referencias bibliográficas}

Aldazabal, A. (13 de abril de 2019). George Forsyth nació en Venezuela, pero sí podrá postular a la presidencia de la República. Correo. https://bit.ly/3gVXyIa

Alonso, L. (2018). El discurso populista en Twitter. Un análisis comparado del estilo comunicativo de los actores políticos populistas de España, Italia, Francia y Reino Unido. [Tesis doctoral, Universitat Jaume I]. Tesis Doctorals en Xarxa. https://www.tdx.cat/handle/10803/663152

Bruce, J. (2007). Nos habíamos choleado tanto. Psicoanálisis y racismo. Fondo Editorial/Universidad de San Martín de Porres.

Cea D’Ancona, M. Á. (2005). La exteriorización de la xenofobia. Revista Española de Investigaciones Sociológicas (REIS), 112(1), 197-230. https://bit.ly/368i7w1

Cea D’Ancona, M. Á. (2009). La compleja detección del racismo y la xenofobia a través de encuesta. Un paso adelante en su medición. Revista Española de Investigaciones sociológicas, (125), 13-45. https://bit.ly/3joDLnF

Cortina, A. (2017). Aporofobia, el rechazo al pobre: Un desafío para la democracia. Ediciones Paidós.

Echebarría, A., y Gonzáles, J. (1996). Images of immigrants: A study on the xenophobia and permeability of intergroup boundaries. European Journal of Social Psychology, 26(3), 341-352. https://doi.org/10.1002/(SICI)1099-0992(199605)26:3\%3C341::AID-EJSP753\%3E3.0.CO;2-4

Espinosa, A., Calderón-Prada, A., Burga, G., y Güímac, J. (2007). Estereotipos, prejuicios y exclusión social en un país multiétnico: el caso peruano. Revista de Psicología, 25(2), 295-338. https://doi.org/10.18800/psico.200702.007

Hernández, R., Fernández, C., y Baptista, M. (2014). Metodología de la investigación (Sexta ed.). McGraw-Hill Interamericana.

Hine, C. (2015). Mixed Methods and Multimodal Research and Internet Technologies. En S. Hesse-Biber y R. Burke (Edits.), The Oxford Handbook of Multimethod and Mixed Methods Research Inquiry (pp. 503521). Oxford University Press. https://doi.org/10.1093/oxfordhb/9780199933624.001.0001

Hjerm, M. (1998). National Identities, National Pride and Xenophobia: A Comparison of Four Western Countries. Acta Sociológica, 41(4), 335-347. https://doi.org/10.1177/000169939804100403

Kreis, R. (2017). \#refugeesnotwelcome: Anti-refugee discourse on Twitter. Discourse y Communication, 11(5), 498-514. https://doi.org/10.1177/1750481317714121

Kursuncu, U., Gaur, M., Lokala, U., Thirunarayan, K., Sheth, A., y Budak Arpinar, I. (2019). Predictive Analysis in Twitter. En N. Agarwal, N. Dokoohaki y S. Tokdemir (Edits.), Emerging Research Challenges and Opportunities in Computational Social Network Analysis and Mining (pp. 67-106). Springer International. https://doi.org/10.1007/978-3-319-94105-9

Global Media Journal México, 18(34), 160-184, enero - junio 2021. 
Manrique, N. (2016). Una alucinación consensual. Redes sociales, cultura y socialización en internet. Fondo editorial PUCP.

Marres, N., y Weltevrede, E. (2013). Scraping the social? Issues in live social research. Journal of Cultural Economy, 6(3), 313-335. https://doi.org/10.1080/17530350.2013.772070

Miller, C., Arcostanzo, F., Smith, J., Krasodomski-Jones, A., Wiedlitzka, S., Jamali, R., y Dale, J. (2017). From Brussels to Brexit: Islamophobia, Xenophobia, Racism and Reports of Hateful Incidents on Twitter. Centre for the Analysis of Social Media, Demos. https://bit.ly/3zJaF8r

Nguyen, N. (2015). I tweet like a white person tbh! \#whitewashed: examining the language of internalized racism and the policing of ethnic identity on Twitter. Social Semiotics, 26(5), 505-523. https://doi.org/10.1080/10350330.2015.1126046

Ott, B. L. (2016). The age of Twitter: Donald J. Trump and the politics of debasement. Critical Studies in Media Communication, 34(1), 59-68. https://doi.org/10.1080/15295036.2016.1266686

Pancorbo, G., Espinosa, A., y Cueto, R. (2011). Representaciones estereotípicas y expresión del prejuicio en el Perú: la mirada desde la pobreza. Revista de Psicología, 29(2), 311-342. https://doi.org/10.18800/psico.201102.006

Portocarrero, G. (2007). Racismo y mestizaje. Fondo Editorial del Congreso del Perú.

Pupiales, J. (9 enero de 2021). Twitter le da espalda a Donald Trump y cierra su cuenta "permanentemente". France 24 . https://bit.ly/3d3k0yd

Redacción Andina. (11 de marzo de 2020). En el Perú hay 23.5 millones de cuentas en Facebook y 7.1 millones en Instagram. Andina, agencia peruana de noticias. https://bit.ly/2SLt1VO

Santos, M. (2014). La discriminación racial, étnica y social en el Perú: balance crítico de la evidencia empírica reciente. Debates en sociología, (39), 5-37. https://bit.ly/3wSOAm8

Serfass, D., Nowak, A., y Sherman, R. (2017). Big data in Psychological Research. En R. Vallacher, S. Read y A. Nowak (Edits.), Computational Social Psychology (pp. 332-348). Taylor \& Francis. https://doi.org/10.4324/9781315173726

Stavenhagen, R. y Negrete. S. (1994). Racismo y xenofobia en tiempos de la globalización. Estudios Sociológicos, 12(34), 9-16. https://bit.ly/3d18iEb

Torre, E. (2019). Migración, racismo y xenofobia en internet: análisis del discurso de usuarios contra los migrantes haitianos en prensa digital mexicana. Revista Pueblos y fronteras digital, 14, 2-28. https://doi.org/10.22201/cimsur.18704115e.2019.v14.401

Traverso, E. (2012). La fábrica del odio. Xenofobia y racismo en Europa. Constelaciones - Revista de teoría crítica, 4, 411-417. https://bit.ly/3y8WyYy

Global Media Journal México, 18(34), 160-184, enero - junio 2021. 
van der Vyver, A. (9-10 diciembre de 2019). An Analyisis of Twitter Discourse on Xenophobia in South Africa. [Ponencia] 23rd PATTAYA International Conference on "Advances in Engineering and Technology" (PAET-19). Pattaya, Tailandia. https://doi.org/10.17758/dirpub7.dir1219105

Vidal, R., y Tenório, R. (2018). A “cordialidade" do povo brasileiro frente à imigração de venezuelanos em Roraima: uma discussão sobre a xenofobia. Revista del CESLA, (22), 327-346. https://bit.ly/2U1ClzT 